\title{
The Impact of Parents' Categorization of Their Own Weight and Their Child's Weight on Healthy Lifestyle Promoting Beliefs and Practices
}

\author{
Allison C. Sylvetsky-Meni, ${ }^{1,2}$ Scott E. Gillepsie, ${ }^{3}$ Trisha Hardy, ${ }^{4}$ and Jean A. Welsh ${ }^{3,4}$ \\ ${ }^{1}$ Department of Exercise and Nutrition Sciences, The George Washington University, 950 New Hampshire Avenue NW, \\ Washington, DC 20052, USA \\ ${ }^{2}$ Graduate Division of Biological and Biomedical Sciences, Laney Graduate School, Emory University, 201 Dowman Drive, \\ Atlanta, GA 30322, USA \\ ${ }^{3}$ Department of Pediatrics, Emory School of Medicine, 1760 Haygood Drive NE, Atlanta, GA 30322, USA \\ ${ }^{4}$ Child Wellness Department, Children's Healthcare of Atlanta, 1577 NE Expressway, Atlanta, GA 30329, USA
}

Correspondence should be addressed to Allison C. Sylvetsky-Meni; asylvets@gwu.edu

Received 7 November 2014; Accepted 2 March 2015

Academic Editor: Aron Weller

Copyright ( 2015 Allison C. Sylvetsky-Meni et al. This is an open access article distributed under the Creative Commons Attribution License, which permits unrestricted use, distribution, and reproduction in any medium, provided the original work is properly cited.

\begin{abstract}
Objective. To evaluate parents' beliefs and practices related to childhood obesity and determine if these are influenced by parent's perception of their own weight or their child's weight. Methods. Parents of obese $(n=689)$ or normal weight $(n=1122)$ children 4-15 years in Georgia, USA, were randomly selected to complete a telephone survey. Frequency of child obesity-related perceptions, beliefs, and practices were assessed, stratified by parent-perceived self-weight and child weight status, and compared using Chisquared tests and multivariate logistic regression. Results. Most parents, regardless of perceived child weight, agreed that child overweight/obesity can cause serious illness (95\%) but only one-half believed it was a problem in Georgia. Many (42.4\%) failed to recognize obesity in their own children. More parents who perceived their child as overweight versus normal weight reported concern about their child's diet and activity and indicated readiness for lifestyle change. Parents' perception of their own weight had little additional impact. Conclusions. While awareness of child overweight as a modifiable health risk is high, many parents fail to recognize it in their own families and communities, reducing the likelihood of positive lifestyle change. Additional efforts to help parents understand their role in facilitating behavior change and to assist them in identifying at-risk children are required.
\end{abstract}

\section{Introduction}

Since the 1970s, the prevalence of childhood obesity has nearly tripled in the United States [1], with the current rate approaching $20 \%$. Obesity in childhood is associated with increased risk of chronic diseases, including type 2 diabetes and nonalcoholic fatty liver disease, as well as depression and other psychosocial conditions [2]. In addition, children who begin their lives overweight or obese are at heightened risk of adult obesity and related comorbidities [3].

Having an overweight or obese parent is known to greatly increase a child's risk of obesity. While research suggests that a proportion of this risk can be attributed to genetics, much is believed to result from environmental factors and is therefore modifiable $[4,5]$. Increased fruit and vegetable consumption, decreased sugar-sweetened beverage consumption, increased physical activity, and decreased use of media and other sedentary activities have been recommended as promising strategies for decreasing obesity risk [6]. Little is known about how to best modify diet and physical activity behaviors that promote a healthy weight. Parental involvement is believed to be a critical component of successful weight management practices in children [7-10]; yet, it is unclear as to why some parents practice behaviors that support the development of a healthy lifestyle, while others do not.

Previous research suggests that how parents perceive the weight status of their children affects the extent to which they 
support positive health and activity behaviors in the family [11-13]. Parents who correctly recognize that their child is overweight more often indicate concern [14] and report intentions to positively modify family lifestyle behaviors [15] compared to parents who incorrectly categorize their overweight or obese children as being healthy weight. This suggests that parents who perceive their children as normal weight, correctly or not, may be doing less to promote healthy diet and activity practices in the family. This is important as behavior patterns established in childhood are associated with future obesity and chronic disease risk [3]. The purpose of this study was to evaluate parental beliefs about childhood obesity and about their child's diet and physical activity practices. We also aimed to determine if these beliefs and practices are modified by parent's perception of their own weight and/or the weight of their child.

\section{Methods}

2.1. Sample. Data were collected from November 2012 to February of 2013, as part of a telephone survey designed to assess the impact of a marketing campaign sponsored by Children's Healthcare of Atlanta. List-assisted, random-digit dialing was used to select households throughout Georgia, USA. Parents or caregivers (referred to hereafter as parents) living in the selected households were called and invited to participate if they had $\geq 1$ child between the ages of 4 and 15 who was either normal weight (defined as 5 th $=$ BMI percentile $<85$ th percentile for their age and sex per the 2000 Centers for Disease Control and Prevention (CDC) Growth Charts) or obese (BMI $\geq 95$ th percentile) [16]. Estimates of BMI were derived using parent-reported values for child height and weight. Parents were excluded from participating if they did not speak either English or Spanish or if they were not a resident of Georgia. Up to six attempts were made to reach parents before replacing them with a randomly selected alternate. If households met the criteria and parents agreed to participate, the interview proceeded immediately. The study protocol was reviewed by the Institutional Review Board at Children's Healthcare of Atlanta and determined to be exempt from federal regulations regarding human subjects research.

Quota sampling was used to ensure recruitment of a large and approximately equal number of parents of children who were obese and parents of children who were normal weight. Respondents with two or more children meeting the survey criteria were asked to complete the interview based on a single, randomly selected child. A total of 1811 parents agreed to participate and fully completed the interview; 1122 were parents of normal weight children and 689 were parents of obese children, based on standard CDC guidelines.

2.2. Measures. Demographic information collected included location of residence (grouped by zip code as metropolitan Atlanta, other urban, and other), family annual income level ( $<\$ 50,000$ or $\geq \$ 50,000$ ), education level (some college or less versus college graduate), sex, race/ethnicity (non-Hispanic white; non-Hispanic black; Hispanic; or other), and parental self-reported weight category (normal weight versus overweight or very overweight/obese (overweight)). Information collected from parents regarding their child included sex, age (years), estimated height (feet and inches), and weight (pounds). These data were used to derive the child's weight status (derived weight status) in order to determine study eligibility. Parents were also asked to report their perception of their child's weight status (perceived weight status) as either underweight or normal weight (normal weight) or overweight or extremely overweight/obese (overweight).

Data were collected using a questionnaire designed to evaluate parental attitudes and practices regarding childhood obesity, as well as their child's diet and physical activity. Responses were measured using a Likert scale, with options ranging from 1 = strongly disagree to $10=$ strongly agree. Interviewers read and recorded parent responses for each of the 18 statements relating to child obesity ( 3 items), their role as parents ( 3 items), their child's weight ( 2 items), their child's diet ( 7 items), and their child's physical activity (3 items). Examples of statements included "I try to educate my child about healthy eating choices," "it costs too much to eat healthy," "technology causes my child to spend less time physically active than I would prefer," "how concerned, if at all, are you about what your child eats", and "as long as my child is happy, it does not matter what he or she weighs" (see Table 2 for a listing of all statements).

2.3. Statistical Analysis. Data analyses were performed using SAS 9.3 (Cary, NC), and statistical significance was evaluated at the 0.05 level. All demographic characteristics were summarized using frequency counts and percentages. Percentages of agreement (score $\geq 7$ out of 10) were calculated for each questionnaire item and compared across parent selfreported weight status (normal weight versus overweight) and parent reported child weight status (normal weight versus overweight) using Chi-square tests of independence or Fisher's exact tests. Multiple logistic regression was employed to calculate adjusted odds ratios and 95\% CI for each question, while controlling for potentially confounding variables including parent sex, race/ethnicity, income, parent education, geographic residence, child sex, and child age. Using parents who perceived their child as normal weight as the reference group, adjusted odds ratios compared their responses to those of parents who perceived their child as overweight. Among the subsample including only parents of children whom they perceived to be overweight, responses were also assessed based on the parents' self-reported weight status (normal weight versus overweight).

\section{Results}

The majority of parents studied were female $(73.1 \%)$ and non-Hispanic white $(65.7 \%)$. Half $(50.8 \%)$ of those surveyed had a college education or higher, and $58.9 \%$ reported an annual household income $\geq \$ 50,000$ (not shown). Parent demographic characteristics stratified by their perception of their child's weight status are shown in Table 1. There were no statistically significant differences in the two parent groups with regard to parent sex, education level, household location, or child sex. Parents who perceived their child as overweight were more likely to be non-Hispanic black (31.2\% versus 
TABLE 1: Characteristics of parents stratified by perceived child's weight status $(n=1811)$ and by parents' self-reported weight status only among parents who perceived their child as overweight.

\begin{tabular}{|c|c|c|c|c|}
\hline \multirow[b]{2}{*}{ Characteristic } & \multicolumn{2}{|c|}{ All parents $(n=1811)$} & \multicolumn{2}{|c|}{ Parents of overweight ${ }^{1}$ child $(n=348)$} \\
\hline & $\begin{array}{l}\text { Child normal weight }^{1} \\
\qquad N=1463\end{array}$ & $\begin{array}{l}\text { Child overweight }^{1} \\
\qquad N=348\end{array}$ & $\begin{array}{l}\text { Normal weight }{ }^{1} \text { parent } \\
\qquad N=125\end{array}$ & $\begin{array}{c}\text { Overweight }^{1} \text { parent } \\
\qquad N=223\end{array}$ \\
\hline \multicolumn{5}{|l|}{ Parent/household } \\
\hline \multicolumn{5}{|l|}{ Sex of parent } \\
\hline Female & $72.3 \%$ & $76.4 \%$ & $72.0 \%$ & $78.9 \%$ \\
\hline Male & $27.7 \%$ & $23.6 \%$ & $28.0 \%$ & $21.1 \%$ \\
\hline \multicolumn{5}{|l|}{ Race/ethnicity } \\
\hline Non-Hispanic white & $67.7 \%$ & $57.2 \%{ }^{* *}$ & $62.6 \%$ & $54.3 \%$ \\
\hline Non-Hispanic black & $23.6 \%$ & $31.2 \%$ & $26.0 \%$ & $34.1 \%$ \\
\hline Hispanic & $4.3 \%$ & $6.1 \%$ & $5.7 \%$ & $6.3 \%$ \\
\hline Other & $4.4 \%$ & $5.5 \%$ & $5.7 \%$ & $5.4 \%$ \\
\hline \multicolumn{5}{|l|}{ Household income $^{1}$} \\
\hline$<\$ 50,000$ & $38.8 \%$ & $50.6 \%{ }^{* * *}$ & $44.5 \%$ & $54.0 \%$ \\
\hline$\geq \$ 50,000$ & $61.2 \%$ & $49.4 \%$ & $55.5 \%$ & $46.0 \%$ \\
\hline \multicolumn{5}{|l|}{ Education } \\
\hline Some college or less & $48.2 \%$ & $53.5 \%$ & $55.2 \%$ & $52.5 \%$ \\
\hline College graduate & $51.8 \%$ & $46.5 \%$ & $44.8 \%$ & $47.5 \%$ \\
\hline \multicolumn{5}{|l|}{ Household location } \\
\hline Metro & $43.7 \%$ & $47.7 \%$ & $46.4 \%$ & $48.4 \%^{*}$ \\
\hline Other urban & $33.8 \%$ & $31.0 \%$ & $25.6 \%$ & $34.1 \%$ \\
\hline Other & $22.5 \%$ & $21.3 \%$ & $28.0 \%$ & $17.5 \%$ \\
\hline \multicolumn{5}{|l|}{ Child } \\
\hline \multicolumn{5}{|l|}{ Weight status (per BMI) } \\
\hline Normal weight & $72.8 \%$ & $16.4 \%^{* * *}$ & $16.8 \%$ & $16.1 \%$ \\
\hline Obese & $27.2 \%$ & $83.6 \%$ & $83.2 \%$ & $83.9 \%$ \\
\hline \multicolumn{5}{|l|}{ Sex of child } \\
\hline Female & $48.1 \%$ & $49.1 \%$ & $40.0 \%$ & $54.3 \% *$ \\
\hline Male & $51.9 \%$ & $50.9 \%$ & $60.0 \%$ & $45.7 \%$ \\
\hline \multicolumn{5}{|l|}{ Age of child } \\
\hline$\leq 11$ years & $59.5 \%$ & $50.0 \%^{* *}$ & $55.2 \%$ & $47.1 \%$ \\
\hline$>11$ years & $40.5 \%$ & $50.0 \%$ & $44.8 \%$ & $52.9 \%$ \\
\hline
\end{tabular}

${ }^{*} P<0.05 ;{ }^{* *} P<0.01 ;{ }^{* * *} P<0.001$.

Two-sided level of significance in relation to their normal weight comparator was tested using Chi-square tests of independence or Fisher's exact tests.

${ }^{1}$ Weight status of parents and children is that as perceived by the parents.

23.6\%) or Hispanic (6.1\% versus $4.3 \%)(P=0.003)$ and to be of low income $(50.6 \%$ versus $38.8 \% ; P<0.001)$ than parents of children perceived as normal weight.

Comparisons between child weight status as perceived by their parent and BMI-derived child weight status (using standard BMI cutoffs) demonstrated that, of the children perceived by their parents to be normal weight, $72.8 \%$ met the BMI-derived criteria for normal weight, while $83.6 \%$ of those perceived by parents to be overweight met the BMIderived criteria of overweight or obese (Table 1). Of those children classified as normal weight using their BMI-derived weight status, $95 \%$ were correctly perceived as normal weight by parents; yet of those children classified overweight/obese using BMI, only $42.2 \%$ were correctly perceived as overweight by their parents.
3.1. Parental Beliefs and Practices Related to Childhood Obesity. Parental beliefs and practices related to child obesity, stratified by their perception of their child's weight, are summarized in Table 2. Among those parents who perceived their child as overweight, responses were also compared based on the parents' self-categorization of their own weight status. Awareness that child obesity can cause serious illness was high among all parents (94.8\%), though less than half believed child obesity to be a serious problem in their state (44.5\%). Parents who perceived their child as overweight were more likely than those who perceived their child as normal weight to report that child obesity was a serious problem (53.5\% versus $42.3 \%, P<0.001$ ). Few parents believed that little can be done because child obesity runs in families; however, more parents who perceived their child as 
TABLE 2: Proportion of parents agreeing with statements related to childhood obesity, diet, and physical activity stratified by child and parent weight status (as perceived by parents).

\begin{tabular}{|c|c|c|c|c|}
\hline \multirow{3}{*}{ Survey item } & \multicolumn{2}{|c|}{ All parents } & \multicolumn{2}{|c|}{ Parents of overweight ${ }^{1}$ child } \\
\hline & Child normal weight $^{1}$ & Child overweight $^{1}$ & Normal weight ${ }^{1}$ parent & Overweight ${ }^{1}$ parent \\
\hline & $N=1463$ & $N=348$ & $N=125$ & $N=223$ \\
\hline \multicolumn{5}{|l|}{ Childhood obesity-general } \\
\hline $\begin{array}{l}\text { Being overweight or obese as a child can } \\
\text { cause serious illnesses }\end{array}$ & $94.7 \%$ & $95.4 \%$ & $92.8 \%$ & $96.9 \%$ \\
\hline $\begin{array}{l}\text { Childhood obesity is a serious problem in } \\
\text { Georgia }\end{array}$ & $42.3 \%$ & $53.5 \%{ }^{* * *}$ & $49.6 \%$ & $55.6 \%$ \\
\hline $\begin{array}{l}\text { Little can be done for overweight children } \\
\text { because weight problems run in families }\end{array}$ & $8.4 \%$ & $12.1 \%^{*}$ & $11.2 \%$ & $12.6 \%$ \\
\hline \multicolumn{5}{|l|}{ Parents as role models } \\
\hline $\begin{array}{l}\text { It is important for me to eat well and be } \\
\text { active because I am a role model for my } \\
\text { child }\end{array}$ & $94.3 \%$ & $93.4 \%$ & $94.4 \%$ & $92.8 \%$ \\
\hline $\begin{array}{l}\text { Parents do not need to do anything about } \\
\text { child overweight as they will grow out of } \\
\text { it }\end{array}$ & $4.9 \%$ & $7.2 \%$ & $8.0 \%$ & $6.7 \%$ \\
\hline \multicolumn{5}{|l|}{ Child's weight } \\
\hline I am concerned with my child's weight & $14.4 \%$ & $73.0 \%{ }^{* * *}$ & $69.6 \%$ & $74.9 \%$ \\
\hline I am ready to address my child's weight & $26.4 \%$ & $58.6 \%{ }^{* * *}$ & $58.4 \%$ & $58.7 \%$ \\
\hline $\begin{array}{l}\text { As long as my child is happy, his/her } \\
\text { weight does not matter }\end{array}$ & $7.5 \%$ & $10.3 \%$ & $11.2 \%$ & $9.9 \%$ \\
\hline \multicolumn{5}{|l|}{ Child's diet } \\
\hline $\begin{array}{l}\text { I try to teach my child about healthy } \\
\text { eating choices }\end{array}$ & $90.1 \%$ & $91.1 \%$ & $93.6 \%$ & $89.6 \%$ \\
\hline I am concerned with what my child eats & $55.8 \%$ & $85.3 \%{ }^{* * *}$ & $84.0 \%$ & $86.1 \%$ \\
\hline $\begin{array}{l}\text { I am trying to change my family's eating } \\
\text { habits for the better }\end{array}$ & $70.5 \%$ & $78.5 \%^{* *}$ & $76.8 \%$ & $70.4 \%$ \\
\hline $\begin{array}{l}\text { My friends and family think it's } \\
\text { important that children eat a healthy diet }\end{array}$ & $87.3 \%$ & $82.1 \%^{*}$ & $81.6 \%$ & $82.4 \%$ \\
\hline $\begin{array}{l}\text { I can provide healthy meals for my child } \\
\text { even when busy }\end{array}$ & $79.6 \%$ & $72.4 \%^{* *}$ & $81.6 \%$ & $67.3 \%{ }^{* *}$ \\
\hline $\begin{array}{l}\text { It takes more time and effort to eat } \\
\text { healthy }\end{array}$ & $50.0 \%$ & $53.5 \%$ & $43.2 \%$ & $59.2 \%{ }^{* *}$ \\
\hline It costs too much to eat healthy & $34.2 \%$ & $39.9 \%^{*}$ & $34.4 \%$ & $43.1 \%$ \\
\hline \multicolumn{5}{|l|}{ Child's physical activity } \\
\hline $\begin{array}{l}\text { I am concerned with how much activity } \\
\text { or exercise my child gets }\end{array}$ & $55.2 \%$ & $83.1 \%{ }^{* * *}$ & $82.4 \%$ & $83.4 \%$ \\
\hline $\begin{array}{l}\text { I am ready to make nutrition and activity } \\
\text { change today }\end{array}$ & $26.4 \%$ & $58.6 \%{ }^{* * *}$ & $58.4 \%$ & $58.7 \%$ \\
\hline $\begin{array}{l}\text { Technology causes my child to spend less } \\
\text { time in physical activity than I would } \\
\text { prefer }\end{array}$ & $35.8 \%$ & $54.3 \%{ }^{* * *}$ & $54.4 \%$ & $54.3 \%$ \\
\hline
\end{tabular}

${ }^{*} P<0.05 ;{ }^{* *} P<0.01 ;{ }^{* * *} P<0.001$.

Two-sided level of significance in relation to their normal weight comparator was assessed using Chi-square tests of independence or Fisher's exact tests.

${ }^{1}$ Weight status of parents and children is that as perceived by the parents.

overweight versus normal weight agreed with this statement (12.1\% and $8.4 \%$, resp., $P=0.034)$.

3.2. Parents as Role Models. Nearly all parents ( $94.1 \%$ overall) recognized the importance of being a healthy role model for their children irrespective of their perceptions of their child's weight. Few parents (5.3\% overall), regardless of their perception of their child's weight status, agreed with the statement that there is little that parents need to do for overweight children as they will grow out of it. 
3.3. Parental Perceptions of Child's Weight. As expected, parents who perceived their child as overweight were significantly more likely to be concerned about their child's weight (73.0\% versus $14.4 \%, P<0.001)$ (Table 2$)$ than parents who perceived their child as normal weight. Parents who perceived their child as overweight were also more likely to report readiness to make nutrition and physical activity changes $(58.6 \%$ versus $26.4 \%, P<0.001)$.

\subsection{Parental Beliefs and Practices Related to Their Child's} Diet. Nearly all parents, regardless of their perception of their child's weight, reported trying to teach their children about healthy eating (90.3\%). Parents who perceived their child as overweight versus normal weight were more likely to be concerned about their family's eating habits, $85.3 \%$ versus $55.8 \%(P<0.001)$, and to be actively working to change them for the better, $78.5 \%$ versus $70.5 \%(P=0.003)$. These parents were less likely to report that they (parents of perceived overweight children) can provide healthy meals even when they are busy (72.4\% versus $79.6 \%, P=0.005)$. Approximately half of all parents agreed that it takes more time to eat healthy (50.7\%), and roughly one-third indicated that it costs too much to eat healthy (35.3\%), with no differences between parents by the perceived weight status of their child.

3.5. Parental Beliefs and Practices Related to Their Child's Physical Activity. As with diet, parents who perceived their child as overweight more frequently reported concern about how much physical activity their child gets $(83.1 \%$ versus $55.2 \%, P<0.001)$ compared to parents who perceived their child as normal weight. Similarly, parents who perceived their child as overweight frequently reported that technology caused their children to spend less time being physically active than they preferred (54.3\% versus $35.8 \%, P<0.001)$.

\subsection{Influence of Parental Self-Reported Weight Status on Child} Obesity Related Beliefs and Practices. Among the subsample including only parents who perceived their child as overweight, few significant differences in responses were observed based on self-reported parental weight status. However, parents self-perceived as overweight were less likely to agree that they could provide healthy meals for their child even when busy $(67.3 \%$ versus $81.6 \%, P=0.004)$ and were more likely to believe that it takes more time and effort to eat healthy $(59.2 \%$ versus $43.2 \%, P=0.004)$.

Adjusted odds ratios (AORs) for each of the 18 questionnaire items are presented in Table 3. After controlling for demographic characteristics including parent sex, race/ethnicity, income, parent education, geographic residence, child sex, and child age, response patterns across the various parent subgroups outline above remained largely the same. Two of the weaker associations involving the questions, "little can be done for overweight children because weight problems run in families" and "it costs too much to eat healthy," were no longer statistically significant after adjusting for parent and child characteristics.

\section{Discussion}

In the present study, we assessed parental beliefs and practices regarding child obesity and their child's diet and physical activity-related behaviors. We then compared finding by parents' perception of their own weight and that of their child. Similar to the results of earlier studies [11, 12, 17], we found that many parents of obese children incorrectly perceived these children as normal weight. Since parents who perceive their obese children as normal weight are less likely to be motivated to make healthy lifestyle behavior changes [15], this highlights the need for increased effort to ensure that children's weight status is regularly and accurately assessed and effectively communicated to parents.

Our results demonstrate that nearly all parents recognize that obesity can cause serious illness and most, regardless of their perception of their own weight status or that of their child, reported that they were trying to educate their children about healthy eating choices and were working to improve their family's diet. Despite this widespread awareness that obesity could lead to serious health complications, our analysis revealed important differences in parents' beliefs and practices depending on how they perceived their child's weight.

Parents who perceived their child as overweight were more likely to view their child's diet, physical activity patterns, and risk of obesity as a health threat and childhood obesity as a serious problem. Despite increased perception of a health threat among parents who perceived their child as overweight, these parents were also more likely to report that little can be done because obesity runs in families and that their child's use of technology prevented them from being physically active. This suggests that education about obesity prevention and assistance to overcome barriers, rather than simply informing parents about risk, are most needed to support their healthy behavior change efforts.

While healthy weight promoting beliefs and practices differed significantly by parental perception of their child's weight, parental self-report of their own weight category had little additional impact. One difference was our finding that parents self-categorized as overweight less frequently indicated being able to provide healthy meals when busy and often reported that it takes more time and effort to eat healthy, similar to barriers described in prior studies $[18,19]$. This suggests a potentially important discrepancy between parental concern, which was high among parents who perceived their child as overweight regardless of their own weight status, and parental ability to take action. While the basis for this discrepancy requires further exploration, one possible explanation may be that parents self-categorized as overweight lack the confidence to promote lifestyle modification [20-22], perhaps because these parents have been unsuccessful in controlling their own weight. Thus, programs devised to increase parental self-efficacy $[9,23]$ may be most effective in promoting health behavior change among overweight and obese parents.

Our study builds upon the existing obesity literature in examining the impact of parental perception of both their 
TABLE 3: Multivariable adjusted odds ratios (AORs) of parental agreement survey items related to childhood obesity, diet, and physical activity $(n=1811)$.

\begin{tabular}{lcc}
\hline Survey item & $\begin{array}{c}\text { All parents of overweight }{ }^{1} \text { versus normal } \\
\text { weight }^{1} \text { child }^{2}\end{array}$ & $\begin{array}{c}\text { Overweight }^{1} \text { versus normal } \\
\text { weight }\end{array}$ parents of overweight $^{1}$ children \\
AOR $(95 \%$ CI) & AOR (95\% CI)
\end{tabular}

Childhood obesity-general

Being overweight or obese as a child can cause serious illnesses

Parents don't need to do anything about child overweight as they will grow out of it

Child's weight

I am concerned with my child's weight

I am ready to address my child's weight

As long as my child is happy, his/her weight

doesn't matter

Child's diet

I try to teach my child about healthy eating choices

I am concerned with what my child eats

I am trying to change my family's eating habits for the better

My friends and family think it's important that children eat a healthy diet

I can provide healthy meals for my child even when busy

It takes more time and effort to eat healthy

It costs too much to eat healthy

Child's physical activity

I am concerned with how much activity or exercise my child gets

I am ready to make nutrition and activity change today

Technology causes my child to spend less time in physical activity than I would prefer
$1.09(0.62-1.93)$

$1.52(1.19-1.94)^{* * *}$

$1.28(0.87-1.91)$

$0.96(0.58-1.60)$

$1.42(0.87-2.31)$

$3.11(0.99-9.73)$

$1.43(0.89-2.31)$

$0.98(0.43-2.21)$

$$
\begin{gathered}
17.06(12.65-23.01)^{* * *} \\
3.76(2.91-4.86)^{* * *}
\end{gathered}
$$

$1.18(0.69-2.01)$

$1.36(0.90-2.07)$

$0.88(0.54-1.42)$

$0.79(0.37-1.69)$

$1.16(0.76-1.78)$

$0.54(0.22-1.37)$

$4.32(3.12-5.98)^{* * *}$

$1.10(0.56-2.14)$

$1.49(1.11-2.00)^{* *}$

$1.11(0.62-1.97)$

$0.69(0.50-0.97)^{*}$

$0.97(0.52-1.81)$

$0.70(0.53-0.93)^{*}$

$0.47(0.27-0.85)^{*}$

$1.15(0.90-1.47)$

$1.83(1.13-2.96)^{*}$

$1.13(0.87-1.46)$

$1.58(0.96-2.61)$

$3.66(2.69-5.00)^{* * *}$

$0.95(0.51-1.77)$

$3.76(2.91-4.86)^{* * *}$

$0.88(0.54-1.42)$

$2.01(1.56-2.58)^{* * *}$

${ }^{*} P<0.05 ;{ }^{* *} P<0.01 ;{ }^{* * *} P<0.001$ (two-sided level of significance in relation to their normal weight comparator).

${ }^{\dagger}$ Odds ratios were calculated using logistic regression and were adjusted for parent gender, race/ethnicity, income, parent education, geographic residence, child gender, and child age.

${ }^{1}$ Weight status of parents and children is that as perceived by the parents.

own weight status and their child's weight category on their obesity-related beliefs and practices. Though the generalizability of our results is limited by the recruitment of a convenience sample of parents, the use of random sampling to identify parents throughout the state helped to increase the geographic representativeness of the sample. While reliance on parent-reported child height and weight as measure of true weight status for purposes of study enrollment may have resulted in some misclassification, inclusion of only children determined to be either normal weight or obese and excluding those in between (determined to be overweight) are expected to have minimized such misclassification. Oversampling of parents with children identified as obese using parent reported height and weight ensured a large enough sample to allow for comparisons with parents of normal weight children. 


\section{Conclusions}

The results of our study demonstrate that awareness of child obesity as a modifiable but serious health risk is high among parents, though many do not recognize its relevance in their own lives. This may result in a failure to promote positive health behaviors in their own family and failure to support childhood obesity prevention efforts in their communities. Further effort is needed to help parents understand the importance of their role in promoting positive lifestyle behaviors and to assist parents in identifying those children whose weight status places them at increased risk, while providing additional counseling and support necessary to make behavior changes.

\section{Disclosure}

All study procedures were reviewed and determined to be exempt human subject research by the Institutional Review Board at Children's Healthcare of Atlanta.

\section{Conflict of Interests}

None of the authors have any conflict of interests to report.

\section{Acknowledgment}

This work was funded by Children's Healthcare of Atlanta.

\section{References}

[1] C. L. Ogden, M. D. Carroll, L. R. Curtin, M. M. Lamb, and K. M. Flegal, "Prevalence of high body mass index in US children and adolescents, 2007-2008," Journal of the American Medical Association, vol. 303, no. 3, pp. 242-249, 2010.

[2] C. L. Ogden, S. Z. Yanovski, M. D. Carroll, and K. M. Flegal, "The epidemiology of obesity," Gastroenterology, vol. 132, no. 6, pp. 2087-2102, 2007.

[3] F. M. Biro and M. Wien, "Childhood obesity and adult morbidities," The American Journal of Clinical Nutrition, vol. 91, no. 5, pp. 1499S-1505S, 2010.

[4] T. V. E. Kral and E. M. Rauh, "Eating behaviors of children in the context of their family environment," Physiology and Behavior, vol. 100, no. 5, pp. 567-573, 2010.

[5] S. Scaglioni, C. Arrizza, F. Vecchi, and S. Tedeschi, "Determinants of children's eating behavior," The American Journal of Clinical Nutrition, vol. 94, no. 6, pp. 2006S-2011S, 2011.

[6] E. Waters, A. de Silva-Sanigorski, B. J. Hall et al., "Interventions for preventing obesity in children," Cochrane Database of Systematic Reviews, no. 3, Article ID CD001871, 2011.

[7] G. A. Hendrie, E. Brindal, N. Corsini, C. Gardner, D. Baird, and R. K. Golley, "Combined home and school obesity prevention interventions for children: what behavior change strategies and intervention characteristics are associated with effectiveness?" Health Education and Behavior, vol. 39, no. 2, pp. 159-171, 2012.

[8] M. Story, K. M. Kaphingst, R. Robinson-O’Brien, and K. Glanz, "Creating healthy food and eating environments: policy and environmental approaches," Annual Review of Public Health, vol. 29, pp. 253-272, 2008.
[9] K. R. Andrews, K. S. Silk, and I. U. Eneli, "Parents as health promoters: a theory of planned behavior perspective on the prevention of childhood obesity," Journal of Health Communication, vol. 15, no. 1, pp. 95-107, 2010.

[10] L. L. Birch and K. K. Davison, "Family environmental factors influencing the developing behavioral controls of food intake and childhood overweight," Pediatric Clinics of North America, vol. 48, no. 4, pp. 893-907, 2001.

[11] A. de la O, K. C. Jordan, K. Ortiz et al., "Do parents accurately perceive their child's weight status?" Journal of Pediatric Health Care, vol. 23, no. 4, pp. 216-221, 2009.

[12] J. Doolen, P. T. Alpert, and S. K. Miller, "Parental disconnect between perceived and actual weight status of children: a metasynthesis of the current research," The Journal of the American Academy of Nurse Practitioners, vol. 21, no. 3, pp. 160166, 2009.

[13] D. Crawford, A. Timperio, A. Telford, and J. Salmon, "Parental concerns about childhood obesity and the strategies employed to prevent unhealthy weight gain in children," Public Health Nutrition, vol. 9, no. 7, pp. 889-895, 2006.

[14] L. C. Moore, C. V. Harris, and A. S. Bradlyn, "Exploring the relationship between parental concern and the management of childhood obesity," Maternal and Child Health Journal, vol. 16, no. 4, pp. 902-908, 2012.

[15] M. H. Park, C. L. Falconer, H. Croker et al., "Predictors of health-related behaviour change in parents of overweight children in England," Preventive Medicine, vol. 62, pp. 20-24, 2014.

[16] R. J. Kuczmarski, C. L. Ogden, S. S. Guo et al., “2000 CDC Growth Charts for the United States: methods and development," Vital and Health Statistics, vol. 11, no. 246, pp. 1-190, 2002.

[17] J. S. Huang, K. Becerra, T. Oda et al., "Parental ability to discriminate the weight status of children: results of a survey," Pediatrics, vol. 120, no. 1, pp. el12-e119, 2007.

[18] A. Slater, J. Bowen, N. Corsini, C. Gardner, R. Golley, and M. Noakes, "Understanding parent concerns about children's diet, activity and weight status: an important step towards effective obesity prevention interventions," Public Health Nutrition, vol. 13 , no. 8, pp. 1221-1228, 2010.

[19] B. J. Turner, N. Navuluri, P. Winkler, S. Vale, and E. Finley, "A qualitative study of family healthy lifestyle behaviors of Mexican-American and Mexican immigrant fathers and mothers," Journal of the Academy of Nutrition and Dietetics, vol. 114, no. 4, pp. 562-569, 2014.

[20] M. Campbell, J. M. Benton, and L. N. Werk, "5-2-1-almost none: parent' perceptions of changing health-related behaviors in their obese child," The Permanente Journal, vol. 13, pp. 4-8, 2009.

[21] L. J. Staniford, J. D. Breckon, R. J. Copeland, and A. Hutchison, "Key stakeholders' perspectives towards childhood obesity treatment: a qualitative study," Journal of Child Health Care, vol. 15, no. 3, pp. 230-244, 2011

[22] M. K. Tanner, "Empowering parents to fight childhood overweight," Journal of the American Dietetic Association, vol. 105, no. 9, pp. 1416-1417, 2005.

[23] K. Campbell, K. Hesketh, A. Silverii, and G. Abbott, "Maternal self-efficacy regarding children's eating and sedentary behaviours in the early years: associations with children's food intake and sedentary behaviours," International Journal of Pediatric Obesity, vol. 5, no. 6, pp. 501-508, 2010. 


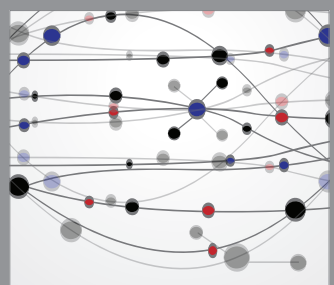

The Scientific World Journal
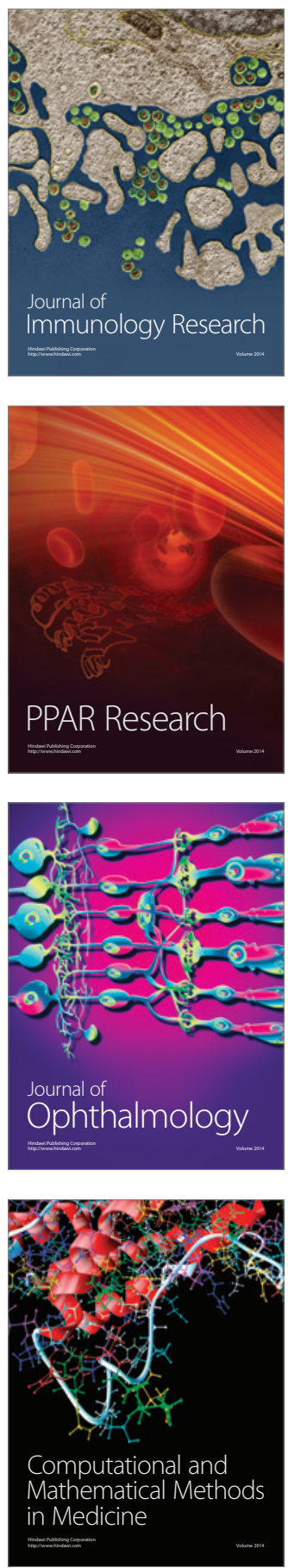

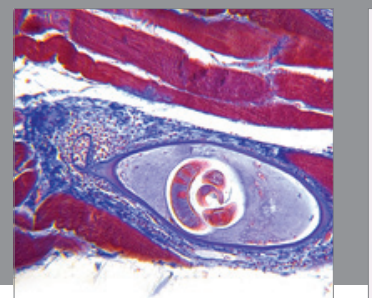

Gastroenterology

Research and Practice
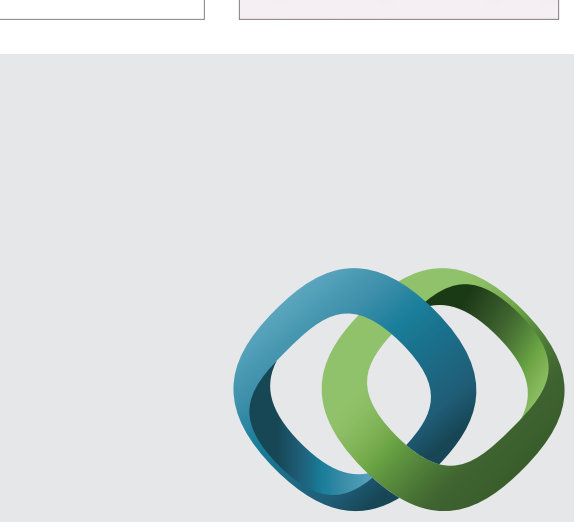

\section{Hindawi}

Submit your manuscripts at

http://www.hindawi.com
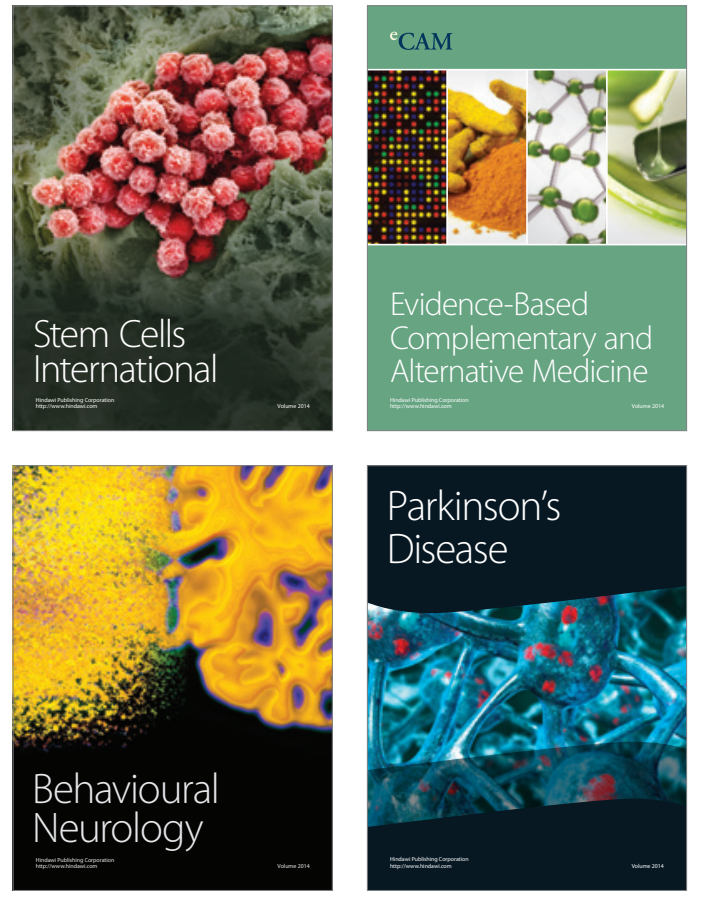
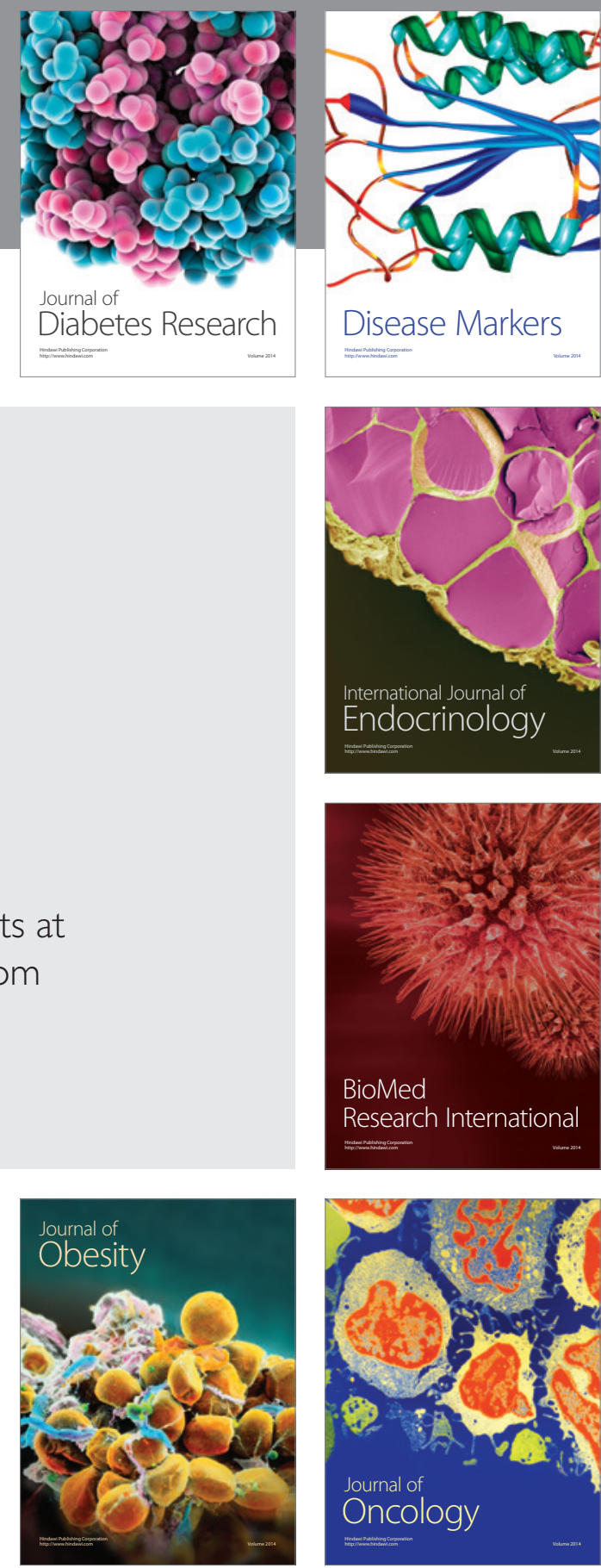

Disease Markers
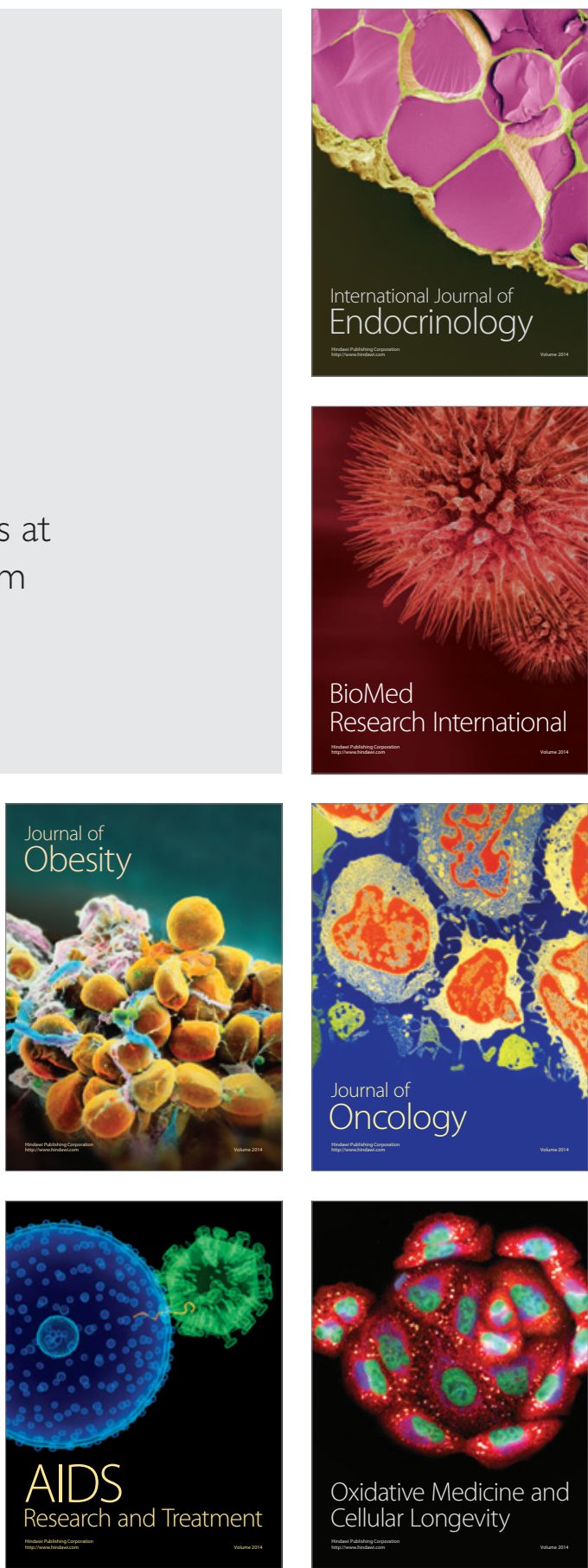